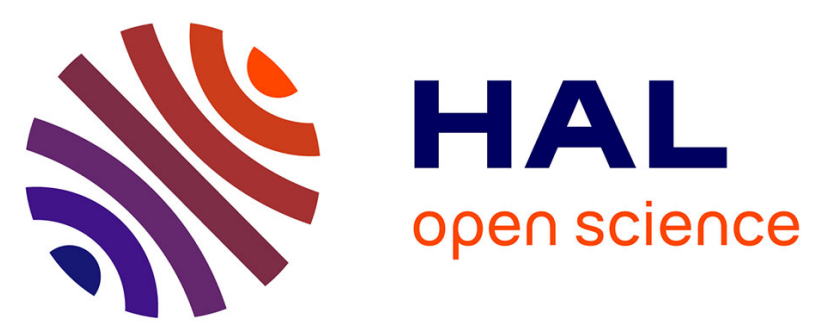

\title{
Long-term occupational trajectories and suicide: a 22-year follow-up of the GAZEL cohort study
}

Marine Azevedo da Silva, Nadia Younès, Ariane Leroyer, Laurent Plancke, Cédric Lemogne, Marcel Goldberg, Mathieu Rivière, Maria Melchior

\section{- To cite this version:}

Marine Azevedo da Silva, Nadia Younès, Ariane Leroyer, Laurent Plancke, Cédric Lemogne, et al.. Long-term occupational trajectories and suicide: a 22-year follow-up of the GAZEL cohort study. Scandinavian Journal of Work, Environment and Health, 2019, 45 (2), pp.158-165. 10.5271/sjweh.3767 . hal-02361876

\section{HAL Id: hal-02361876 https://hal.sorbonne-universite.fr/hal-02361876}

Submitted on 13 Nov 2019

HAL is a multi-disciplinary open access archive for the deposit and dissemination of scientific research documents, whether they are published or not. The documents may come from teaching and research institutions in France or abroad, or from public or private research centers.
L'archive ouverte pluridisciplinaire HAL, est destinée au dépôt et à la diffusion de documents scientifiques de niveau recherche, publiés ou non, émanant des établissements d'enseignement et de recherche français ou étrangers, des laboratoires publics ou privés. 


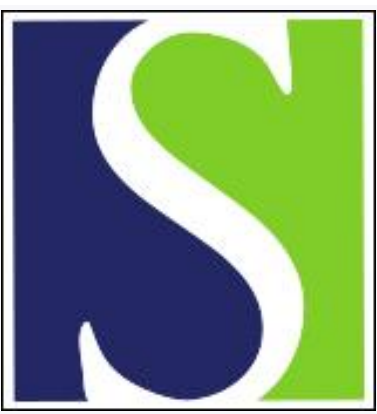

\section{Original article}

Scand J Work Environ Health Online-first -article

doi:10.5271/sjweh.3767

Long-term occupational trajectories and suicide: a 22-year follow-up of the GAZEL cohort study

by Azevedo Da Silva M, Younès N, Leroyer A, Plancke L, Lemogne $C$, Goldberg M, Rivière M, Melchior M

Over the course of a 21-year follow-up, participants with stable low occupational grade were at elevated risk of suicide compared to workers with intermediate/high occupational grade who experienced career development. Workplace suicide prevention could focus on workers with limited opportunities for occupational advancement. Policies that limit opportunities for occupational advancement may disadvantage especially vulnerable workers.

Affiliation: INSERM, Sorbonne Université, Institut Pierre Louis d'Epidémiologie et de Santé Publique IPLESP, Department of Social Epidemiology (ERES), Paris, France. marine.azevedo@inserm.fr

Refers to the following text of the Journal: 2018;44(1):1-110

Key terms: cohort study; depression; GAZEL; GAZEL cohort study; long-term occupational trajectory; longitudinal cohort; mental health; occupational trajectory; psychosocial; risk; risk; risk; risk; risk; socioeconomic position; suicide; trajectory 


\title{
Long-term occupational trajectories and suicide: a 22-year follow-up of the GAZEL cohort study
}

\author{
by Marine Azevedo Da Silva, PhD, 1, 2, 3 Nadia Younès, MD, PhD, ${ }^{2,4}$ Ariane Leroyer, MD, PhD, ${ }^{5}$ Laurent Plancke, PhD, ${ }^{6}$ Cédric \\ Lemogne, MD, PhD, $7,8,9$ Marcel Goldberg, MD, PhD, ${ }^{10}$ Mathieu Rivière, MSc, ${ }^{1,11}$ Maria Melchior, PhD ${ }^{1}$
}

\begin{abstract}
Azevedo Da Silva M, Younès N, Leroyer A, Plancke L, Lemogne C, Goldberg M, Rivière M, Melchior M. Long-term occupational trajectories and suicide: a 22-year follow-up of the GAZEL cohort study. Scand J Work Environ Health - online first. doi:10.5271/sjweh.3767
\end{abstract}

Objective Most suicides occur among individuals of working age. Risk is elevated in some occupational groups, however relations between long-term occupational trajectories and suicide are not well known. We describe career-long occupational trajectories and examine their influence on suicide.

Methods Data come from GAZEL, a French cohort study set among employees of a large national utilities company. Occupational grade was obtained from company records from the time of hiring (1953-1988). Groupbased trajectory models were used to define occupational trajectories over a mean time period of 25.0 (standard deviation 6.5) years. Causes of mortality, coded using the International Classification of Diseases, were recorded from 1993-2014 and studied using Cox regression models.

Results Of the 20452 participants included in the study, 73 died by suicide between 1993-2014. Results suggested an increased risk of suicide [hazard ratio (HR) 2.57, 95\% confidence interval (CI) 1.08-6.15] among participants with persistently low occupational grade compared to those with higher occupational grade and career development. After adjustment for all covariates, especially psychological factors, this association was reduced and no longer statistically significant (HR 2.02, 95\% CI 0.82-4.95).

Conclusions Persistently low occupational grade could be related to an elevated risk of suicide. This association partly reflects psychological and health characteristics, which can influence occupational trajectories and be reinforced by unfavorable work conditions.

Key terms depression; longitudinal cohort; mental health; psychosocial; risk; socioeconomic position.

According to the Global Health Observatory data repository of the World Health Organization (WHO), 788000 deaths by suicide occurred worldwide in 2015 , representing an annual age-standardized suicide rate of 10.7 per 100000 . Suicide is a multifactorial event, associated with characteristics of societies, communities, health systems and individuals (1). Among these, work char- acteristics appear to play a complex role. On the one hand, work is protective: individuals seeking employment have a higher risk of suicide than those who are employed (2). However the majority of suicides occur among individuals who are working (3) and some trades appear to confer especially high risk (eg, agriculture, the health sector, police and military) (4). Additionally,

1 INSERM, Sorbonne Université, Institut Pierre Louis d'Epidémiologie et de Santé Publique IPLESP, Department of Social Epidemiology (ERES), Paris, France.,

2 EA 40-47 University of Versailles Saint-Quentin, Versailles, France.

3 Department of Epidemiology, Mailman School of Public Health, Columbia University, New York, NY, USA.

4 Academic Unit of psychiatry for adults, Versailles Hospital, Versailles, France.

5 Univ. Lille, EA 4483 - IMPECS - IMPact of Environmental ChemicalS on human health, Lille, France; CHU Lille, Pôle de Santé Publique, Lille, France.

6 Fédération régionale de recherche en psychiatrie et santé mentale Hauts-de-France, Lille, France.

7 Université Paris Descartes, Sorbonne Paris Cité, Faculté de Médecine, Paris, France.

8 AP-HP, Paris-Ouest University Hospitals, Psychiatry department, Paris, France.

9 Inserm, U894, Centre for Psychiatry and Neuroscience, Paris, France.

10 Inserm UMS 11, Population-based Epidemiologic Cohort Unit, Villejuif, France.

11 Department of Infectious Diseases, Centre Hospitalier Régional, Orléans, France.

Correspondence to: Marine Azevedo Da Silva, INSERM, Sorbonne Université, Institut Pierre Louis d'Epidémiologie et de Santé Publique IPLESP, Department of Social Epidemiology (ERES), Paris, France. [E-mail: marine.azevedo@inserm.fr] 
there is an occupational gradient in relation to suicide, whereby individuals in less qualified occupations are more likely to commit suicide than those who are at the top of the hierarchy (5). To date, despite abundant anecdotal evidence regarding the role of psychosocial work factors with regard to suicide, this association remains unclear $(2,6)$. Moreover, relations between long-term work patterns and suicide are not fully described.

\section{Aims of the study}

We used longitudinal data from the French GAZEL cohort study to describe long-term occupational trajectories over a mean time period of 25.0 years, and explore their association with the risk of suicide over a 22 -year follow-up period.

\section{Methods}

\section{Study population}

The GAZEL cohort study was established in 1989 (7). Briefly, the target population consists of employees of the French national gas and electricity company (Electricité de France-Gaz de France - EDF-GDF) who, up until the company was privatized in the 2000s, benefited from job stability and opportunities for occupational mobility. Typically, employees were hired when they were in their 20s and stayed with the company until retirement (usually around 55 years of age). This offers the unique opportunity to characterize participants' occupational trajectories across their whole career. Since inception, $<1 \%$ of participants have been lost to follow-up.

In 1989, GAZEL recruited 20625 volunteers (15 011 men and 5614 women), aged 35-50 years, who since then receive an annual questionnaire collecting data on health, lifestyle, individual, familial, social, occupational risk factors and life events. Prior to privatization, EDF-GDF had an occupational health department, a medical insurance, a detailed health surveillance system and paid employees' retirement pensions thereby allowing for a thorough follow-up. The GAZEL study received approval from the national commission overseeing ethical data collection in France (Commission Nationale Informatique et Libertés).

For the present analyses, we restricted the study sample to 20452 participants with data on occupational grade who were alive and part of the cohort in 1993 when key covariates were measured (figure 1). During the follow-up between 1993 and 2014 [median of 21.9, standard deviation (SD) 3.2, years], 2081 deaths occurred including 73 suicides.

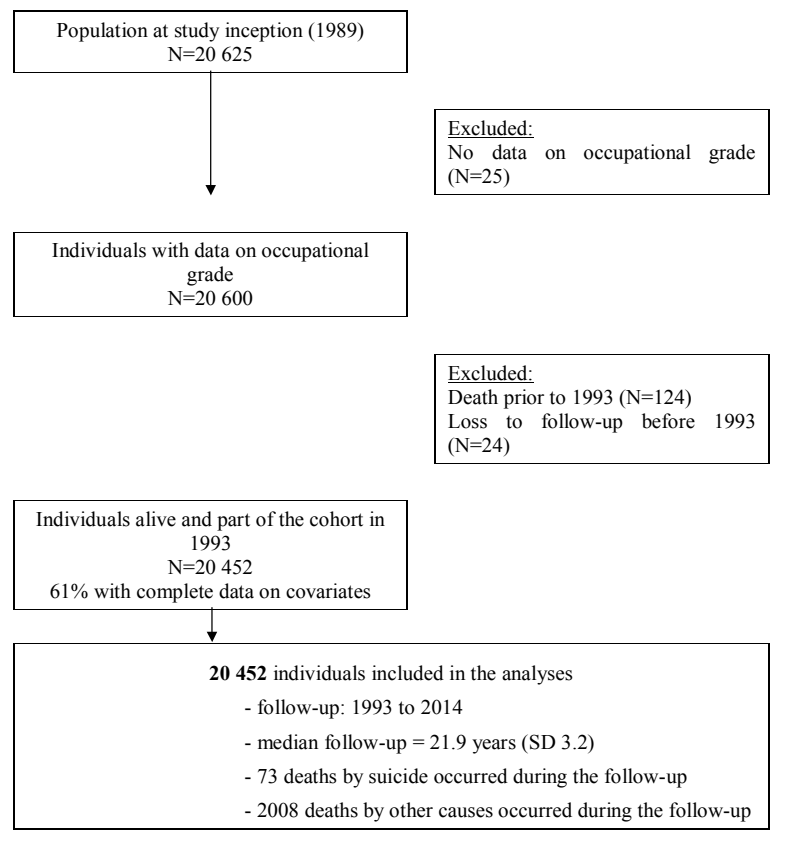

Figure 1. Flowchart for risk of suicide analyses.

\section{Measurements}

Mortality. The date of death was obtained from company records. The cause of death, available from the French national cause-of-death registry (CépiDC, INSERM) and linked to GAZEL, was available from baseline (ie, 1 January 1993) to 31 December 2014 and coded using the International Classification of Disease (ICD). Completed suicides correspond to the codes E950-E959 (9 $9^{\text {th }}$ revision) and $\mathrm{X} 60-\mathrm{X} 84$ (10 ${ }^{\text {th }}$ revision).

Occupational grade. Occupational grade was obtained from company records, from the time of hiring (between 1953 and 1988) to the baseline for this analysis (1993), leading to a mean time period of 25.0 years (SD 6.5), prior to suicide assessment (1993-2014, 22-year followup). Occupational grade was coded according to the French national job classification (Institut National de la Statistique et des Etudes Economiques: INSEE): high grade (managers), intermediate grade (associate professionals and technicians), clerks, and manual workers.

\section{Covariates}

Covariates were measured at baseline (1993), except retirement ascertained throughout the follow-up. Sociodemographic characteristics included age, sex, partner status (married/living with a partner versus single/ divorced/separated/widowed) and retirement (no versus yes). Smoking and alcohol consumption were assessed 
using a self-administered questionnaire. Smoking status was categorized as: non-smoker, former smoker or smoker ( $\geq 1$ cigarette/day). Alcohol use, assessed by the number of alcoholic drinks per week, was categorized as none, moderate (1-27 for men, 1-20 for women) or heavy ( $\geq 28$ for men, $\geq 21$ for women). Psychosocial characteristics included stressful life events 12 months prior the survey (hospitalization, relative's death, relative's hospitalization, relative's unemployment; 0 versus $\geq 1$ ), depressive symptoms were measured using the Center for Epidemiologic Studies Depression (CESD) scale (continuous score 0-60) and cognitive hostility, a personality trait linked with increased suicide risk (8), was assessed with the Buss and Durkee Hostility Inventory (the sub-scales "resentment" and "suspicion" of the BDHI; continuous score 0-18).

\section{Statistical analysis}

Occupational trajectories from the time of hiring (1953-1988) to baseline (1993) were defined using group-based trajectory models (9). This method empirically groups together individuals with similar trajectories over time. Models including 2-6 trajectories were tested. The two criteria used to determine the optimal number of trajectories were (i): Bayesian information criterion (lower absolute values correspond to better fit) and (ii) posterior probabilities of group assignment (the likelihood that an individual belongs to a given trajectory; all trajectories should have a mean posterior probability $\geq 0.70$ and each trajectory contains $\geq 5 \%$ of participants). We also verified that each trajectory included $\geq 5 \%$ of participants. This method was implemented with the traj package (available from http:// www.andrew.cmu.edu/user/bjones/traj) for Stata 14 (StataCorp, College Station, YX, USA).

Missing covariate data were imputed using multiple imputations (40 datasets), with the fully conditional specification (FCS) method (10), based on all available data on suicide and covariates.

To examine relationships between occupational trajectories and suicide deaths we used Cox proportionalhazards regression models with age as the time scale. The proportional hazards assumptions were confirmed by Schoenfeld tests. Hazard ratios (HR) and 95\% confidence intervals (CI) of incident suicide were computed from 1993 to the date of suicide, death by another cause, or 31 December 2014, whichever occurred first. Statistical analyses controlled for potentially confounding variables selected based on the literature and formal bivariate tests (considered relevant at $\mathrm{P} \leq 0.1$ ). In Model 1 , HR were adjusted for socio-demographic factors (sex, partner status and retirement). Model 2 additionally controlled for smoking and alcohol use. Model 3 further controlled for psychosocial characteristics (depressive symptoms, stressful life events, cognitive hostility). Confounding variables were ascertained at baseline (1993), except retirement used as a time-varying covariate.

\section{Sensitivity analysis}

To test the robustness of our findings, we conducted further sensitivity analyses. First, in order to address the possibility that some people might describe conditions at baseline when they actually consider committing suicide, we repeated the Cox proportional-hazards regression models in the main analysis by delaying the start of the follow-up by one (follow-up 1994-2014), two (follow-up 1995-2014) and three years (follow-up 1996-2014). Second, in order to address the possibility that some people commit suicide in older age due to being alone (eg, widowed) or seriously ill (eg, cancer), we repeated the Cox proportional-hazards regression models in the main analysis by ending the follow-up at 70 and 65 years of age. Third, in order to address the possibility that occupational grade at one point in time might predict suicide risk similarly to occupational trajectories, we repeated the Cox proportional-hazards regression models in the main analysis using occupational grade at baseline (1993) as independent variable.

\section{Results}

Figure 2 shows participants' occupational trajectories. Four trajectories were identified (i): stable manual workers (8.7\%) (ii); manual workers with career development (13.4\%) (iii); clerks with career development (56.4\%) (iv); intermediate/high occupational grade workers with career development (21.5\%). Mean posterior probabilities were estimated between 0.85-0.97.

Baseline participant characteristics as a function of occupational trajectories are presented in table 1 . Among the 20452 GAZEL cohort members included in the analysis, $1755(8.6 \%)$ were stable manual workers, $2315(11.3 \%)$ were manual workers with career development, 12434 (60.8\%) were clerks with career development and 3948 (19.3\%) were intermediate/high occupational grade workers with career development.

During follow-up (median of 21.9, SD 3.2, years), 73 suicide deaths occurred ( $0.4 \%$ of the sample): 12 $(0.7 \%)$ among stable manual workers, $12(0.5 \%)$ among manual workers with career development, $40(0.3 \%)$ among clerks with career development and $9(0.2 \%)$ among intermediate/high occupational grade workers with career development.

Table 2 shows associations between occupational trajectories and suicide. After adjustment for socio-demographic characteristics (Model 1), participants who were 


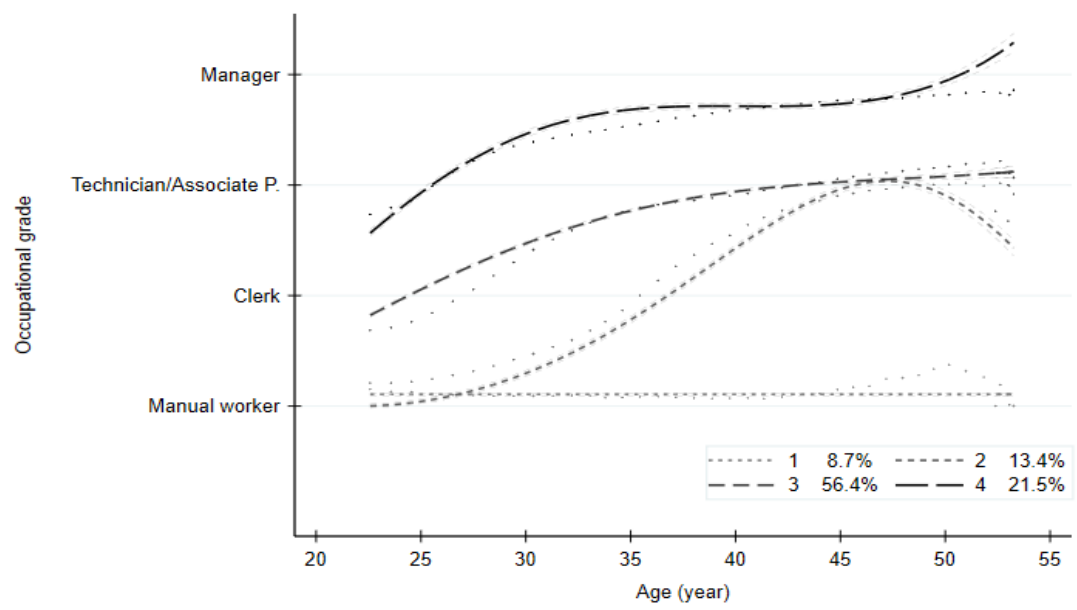

Figure 2. Occupational trajectories according to age from the time of hiring to 1993 (study baseline) of the GAZELstudy participants $(n=20,600)$. Trajectory 1, stable manual workers; trajectory 2, manual workers with career development; trajectory 3 , clerkswithcareer development; trajectory 4, participantswith intermediate/ high occupational grade with career development.

Table 1. Participants' baseline characteristics (1993) by occupational trajectory: the GAZEL cohort study, $N=20452$, chi-square (categorical variables) and t-tests (continuous variables), P-value. Results are of participants with imputed missing data. [CESD=Center for Epidemiologic Studies Depression: $\mathrm{SD}=$ standard deviation].

\begin{tabular}{|c|c|c|c|c|c|c|c|c|c|c|c|c|c|c|c|c|c|}
\hline \multirow[t]{2}{*}{ Variables } & \multicolumn{4}{|c|}{ Trajectory $1^{\mathrm{a}}(\mathrm{N}=1755)$} & \multicolumn{4}{|c|}{ Trajectory $2^{\mathrm{b}}(\mathrm{N}=2315)$} & \multicolumn{4}{|c|}{ Trajectory $3^{c}$ ( $\left.N=12434\right)$} & \multicolumn{4}{|c|}{ Trajectory $4^{d}(\mathrm{~N}=3948)$} & \multirow[t]{2}{*}{ P-value ${ }^{e}$} \\
\hline & $\mathrm{N}$ & $\%$ & Mean & SD & $\mathrm{N}$ & $\%$ & Mean & SD & $\mathrm{N}$ & $\%$ & Mean & SD & $\mathrm{N}$ & $\%$ & Mean & SD & \\
\hline Sex & & & & & & & & & & & & & & & & & $<0.001$ \\
\hline Men & 1727 & 98.4 & & & 2274 & 98.2 & & & 7497 & 60.3 & & & 3382 & 85.7 & & & \\
\hline Women & 28 & 1.6 & & & 41 & 1.8 & & & 4937 & 39.7 & & & 566 & 14.3 & & & \\
\hline Age & & & 47.8 & 0.07 & & & 48.4 & 0.06 & & & 46.9 & 0.03 & & & 47.7 & 0.05 & $<0.001$ \\
\hline Partner status & & & & & & & & & & & & & & & & & $<0.001$ \\
\hline Married/living with a partner & 1597 & 91.0 & & & 2122 & 91.7 & & & 10657 & 85.7 & & & 3569 & 90.4 & & & \\
\hline $\begin{array}{l}\text { Single/divorced/separated/ } \\
\text { widowed }\end{array}$ & 158 & 9.0 & & & 193 & 8.3 & & & 1778 & 14.3 & & & 379 & 9.6 & & & \\
\hline Smoking & & & & & & & & & & & & & & & & & $<0.001$ \\
\hline Non-smokers & 616 & 35.2 & & & 804 & 34.8 & & & 5913 & 47.6 & & & 1662 & 42.1 & & & \\
\hline Former smokers & 719 & 40.9 & & & 1015 & 43.8 & & & 4067 & 32.7 & & & 1507 & 38.2 & & & \\
\hline Smokers & 420 & 23.9 & & & 496 & 21.4 & & & 2454 & 19.7 & & & 779 & 19.7 & & & \\
\hline Alcohol use & & & & & & & & & & & & & & & & & $<0.001$ \\
\hline None & 193 & 11.0 & & & 230 & 9.9 & & & 1836 & 14.8 & & & 326 & 8.3 & & & \\
\hline Moderate & 1223 & 69.7 & & & 1686 & 72.9 & & & 9214 & 74.1 & & & 3133 & 79.3 & & & \\
\hline Heavy & 339 & 19.3 & & & 399 & 17.2 & & & 1384 & 11.1 & & & 489 & 12.4 & & & \\
\hline $\begin{array}{l}\text { Stressful life events } \\
\text { (previous } 12 \text { months) }\end{array}$ & & & & & & & & & & & & & & & & & $<0.001$ \\
\hline 0 & 1025 & 58.4 & & & 1318 & 56.9 & & & 7226 & 58.1 & & & 2451 & 62.1 & & & \\
\hline$\geq 1$ & 730 & 41.6 & & & 997 & 43.1 & & & 5208 & 41.9 & & & 1497 & 37.9 & & & \\
\hline CESD score & & & 13.5 & 0.27 & & & 12.5 & 0.21 & & & 14.0 & 0.11 & & & 11.8 & 0.15 & $<0.001$ \\
\hline Cognitive hostility score & & & 7.3 & 0.11 & & & 6.5 & 0.09 & & & 6.2 & 0.04 & & & 4.9 & 0.06 & $<0.001$ \\
\hline Suicide deaths & & & & & & & & & & & & & & & & & 0.032 \\
\hline No & 1743 & 99.3 & & & 2303 & 99.5 & & & 12394 & 99.7 & & & 3939 & 99.8 & & & \\
\hline Yes & 12 & 0.7 & & & 12 & 0.5 & & & 40 & 0.3 & & & 9 & 0.2 & & & \\
\hline
\end{tabular}

a Stable manual workers.

${ }^{\mathrm{b}}$ Manual workers with career development.

${ }^{c}$ Clerks with career development.

d Participants with intermediate/high occupational grade with career development.

e Test for homogeneity among different occupational trajectories classes.

stable manual workers (HR 2.57, 95\% CI 1.08-6.15) had an increased risk of suicide, compared with participants with intermediate/high occupational grade with career development. Additional adjustment for health behaviors (Model 2; HR 2.39, 95\% CI 1.00-5.73) and psychosocial characteristics (Model 3; HR 2.02, 95\% CI 0.82-4.95) reduced the magnitude of this association and rendered it statistically non-significant. The risk of suicide among manual workers (HR=1.99, 95\% CI 0.83-4.76) or clerks
(HR 1.59, 95\% CI 0.76-3.30) who experienced career development was not statistically significant.

In the first sensitivity analysis (table 3 ), we delayed the start of the follow-up by one (follow-up 1994-2014), two (follow-up 1995-2014) and three years (follow-up 1996-2014). Statistical analyses were respectively based on 20395 (69 suicides), 20352 (63 suicides), and 20 305 (57 suicides) individuals. Overall, the results were similar to the main analysis. The magnitude of the 
Table 2. Association between occupational trajectory and risk of suicide (1993-2014): the GAZEL cohort study, N=20 452, Cox proportional-hazards regression models. Results are of participants with imputed missing data. Confounding variables were used at baseline (1993), except retirement that was use as time-varying covariates in the analysis. [PY= person-years; IR=incidence rate; $H R=$ hazard ratio; $\mathrm{Cl}=$ =confidence interval].

\begin{tabular}{|c|c|c|c|c|c|c|c|c|c|c|c|c|}
\hline \multirow{2}{*}{$\begin{array}{l}\text { Occupational } \\
\text { trajectories }\end{array}$} & \multirow{2}{*}{$\begin{array}{l}\mathrm{N} \text { suicide } \\
\text { death/N }\end{array}$} & \multirow[t]{2}{*}{ PY } & \multirow{2}{*}{$\begin{array}{c}\text { IR per } \\
100000 \mathrm{PY}\end{array}$} & \multicolumn{3}{|c|}{ Model $1^{\text {a }}$} & \multicolumn{3}{|c|}{ Model $2^{b}$} & \multicolumn{3}{|c|}{ Model $3^{c}$} \\
\hline & & & & HR & $95 \% \mathrm{Cl}$ & $\mathrm{P}$-value & HR & $95 \% \mathrm{Cl}$ & P-value & HR & $95 \% \mathrm{Cl}$ & P-value \\
\hline Trajectory $1 \mathrm{~d}$ & $12 / 1755$ & 35779 & 33.54 & 2.57 & $1.08-6.15$ & 0.033 & 2.39 & $1.00-5.73$ & 0.050 & 2.02 & $0.82-4.95$ & 0.124 \\
\hline Trajectory $2^{\mathrm{e}}$ & $12 / 2315$ & 48310 & 24.84 & 1.99 & $0.83-4.76$ & 0.121 & 1.95 & $0.81-4.66$ & 0.134 & 1.78 & $0.74-4.31$ & 0.201 \\
\hline Trajectory $3^{f}$ & $40 / 12434$ & 262293 & 15.25 & 1.59 & $0.76-3.30$ & 0.218 & 1.52 & $0.73-3.17$ & 0.266 & 1.40 & $0.67-2.95$ & 0.373 \\
\hline Trajectory $4^{g}$ & $9 / 3948$ & 83929 & 10.72 & & reference & & & reference & & & reference & \\
\hline
\end{tabular}

adjusted for socio-demographic characteristics (sex, partner status, retirement).

${ }^{\mathrm{b}}$ Adjusted for health behaviors (smoking, alcohol use).

${ }^{c}$ Adjusted for psychosocial characteristics (stressful life events, depressive symptoms, cognitive hostility).

d Stable manual workers.

e Manual workers with career development.

${ }^{\mathrm{f}}$ Clerks with career development.

g Participants with intermediate/high occupational grade with career development.

Table 3. Association between occupational trajectory and risk of suicide delaying the beginning of follow-up by one, two, or three years: the GAZEL cohort study, Cox proportional-hazards regression models. Results are of participants with imputed missing data. Confounding variables were used at baseline (1993), except retirement that was use as time-varying covariates in the analysis. [PY=person-years; IR=incidence rate; HR=hazard ratio; $\mathrm{Cl}=$ confidence interval].

\begin{tabular}{|c|c|c|c|c|c|c|c|c|c|c|c|c|}
\hline \multirow{2}{*}{$\begin{array}{l}\text { Occupational } \\
\text { trajectories }\end{array}$} & \multirow{2}{*}{$\begin{array}{l}\text { N suicide } \\
\text { death/N }\end{array}$} & \multirow[t]{2}{*}{ PY } & \multirow{2}{*}{$\begin{array}{c}\text { IR per } \\
100000 \text { PY }\end{array}$} & \multicolumn{3}{|c|}{ Model $1^{\mathrm{a}}$} & \multicolumn{3}{|c|}{ Model $2^{b}$} & \multicolumn{3}{|c|}{ Model $3^{c}$} \\
\hline & & & & $\mathrm{HR}$ & $95 \% \mathrm{Cl}$ & P-value & HR & $95 \% \mathrm{Cl}$ & P-value & $\mathrm{HR}$ & $95 \% \mathrm{Cl}$ & P-value \\
\hline \multicolumn{13}{|c|}{$\begin{array}{l}\text { Beginning of follow-up } \\
\text { delayed by one year } \\
(1994-2014)\end{array}$} \\
\hline Trajectory $1^{\mathrm{d}}$ & $12 / 1746$ & 34028 & 35.26 & 2.57 & $1.08-6.15$ & 0.034 & 2.43 & $1.01-5.82$ & 0.047 & 2.05 & $0.84-5.03$ & 0.115 \\
\hline Trajectory $2^{\mathrm{e}}$ & $11 / 2308$ & 45997 & 23.08 & 1.82 & $0.75-4.42$ & 0.187 & 1.78 & $0.73-4.33$ & 0.204 & 1.62 & $0.66-3.99$ & 0.292 \\
\hline Trajectory $3^{f}$ & $37 / 12,399$ & 249876 & 14.81 & 1.48 & $0.71-3.10$ & 0.299 & 1.43 & $0.68-3.00$ & 0.345 & 1.32 & $0.62-2.79$ & 0.471 \\
\hline \multicolumn{13}{|c|}{$\begin{array}{l}\text { Beginning of follow-up } \\
\text { delayed by two years } \\
\text { (1995-2014) }\end{array}$} \\
\hline Trajectory $1^{\mathrm{d}}$ & $12 / 1739$ & 32288 & 37.17 & 2.95 & $1.19-7.27$ & 0.019 & 2.82 & $1.14-6.98$ & 0.025 & 2.47 & $0.98-6.25$ & 0.056 \\
\hline Trajectory $2 \mathrm{e}$ & $11 / 2300$ & 43695 & 25.17 & 2.05 & $0.82-5.14$ & 0.125 & 2.03 & $0.81-5.08$ & 0.133 & 1.89 & $0.75-4.81$ & 0.179 \\
\hline Trajectory $3^{f}$ & $32 / 12376$ & 237491 & 13.47 & 1.41 & $0.64-3.10$ & 0.394 & 1.37 & $0.62-3.02$ & 0.434 & 1.29 & $0.58-2.86$ & 0.536 \\
\hline Trajectory $4^{g}$ & $8 / 3937$ & 76035 & 10.52 & & reference & & & reference & & & reference & \\
\hline \multicolumn{13}{|c|}{$\begin{array}{l}\text { Beginning of follow-up } \\
\text { delayed by three years } \\
\text { (1996-2014) }\end{array}$} \\
\hline Trajectory $1 \mathrm{~d}$ & $12 / 1730$ & 30557 & 39.27 & 3.49 & $1.36-8.95$ & 0.009 & 3.40 & $1.32-8.76$ & 0.011 & 2.96 & $1.13-7.79$ & 0.028 \\
\hline Trajectory $2^{\mathrm{e}}$ & $11 / 2291$ & 41402 & 26.57 & 2.39 & $0.92-6.22$ & 0.075 & 2.38 & $0.91-6.20$ & 0.077 & 2.21 & $0.84-5.83$ & 0.109 \\
\hline Trajectory $3^{f}$ & $27 / 12358$ & 225126 & 11.99 & 1.38 & $0.59-3.23$ & 0.452 & 1.36 & $0.58-3.17$ & 0.479 & 1.27 & $0.54-2.99$ & 0.586 \\
\hline Trajectory $4^{g}$ & $7 / 3926$ & 72105 & 9.71 & & reference & & & reference & & & reference & \\
\hline
\end{tabular}

adjusted for socio-demographic characteristics (sex, partner status, retirement).

${ }^{\mathrm{b}}$ Adjusted for health behaviors (smoking, alcohol use).

${ }^{c}$ Adjusted for psychosocial characteristics (stressful life events, depressive symptoms, cognitive hostility).

'Stable manual workers.

e Manual workers with career development.

${ }^{\mathrm{f}}$ Clerks with career development.

g Participants with intermediate/high occupational grade with career development.

association was highest for stable manual workers (fully adjusted association statistically significant when the start of the follow-up was delayed by three years) and for manual workers with career development

In a second sensitivity analysis (table 4), we censured the follow-up at 70 and 65 years of age. Statistical analyses were based on 20452 individuals and respectively 70 and 65 suicides occurred. The magnitude of observed associations was reduced but conclusions were unchanged compared to the main analysis.

In a third sensitivity analysis (table 5), we examined the association between occupational grade measured at one point in time (baseline, 1993) and suicide. After adjustment for socio-demographic characteristics (Model 1), manual workers (HR 2.58, 95\% CI 1.07-6.27) and participants with intermediate grade (HR 2.34, 95\% CI 1.20-4.53) had an increased risk of suicide, compared with participants with high grade. 
Table 4. Association between occupational trajectory and risk of suicide with the end of follow-up at 70 or 65 years of age: the GAZEL cohort study, Cox proportional-hazards regression models. Results are of participants with imputed missing data. Confounding variables were used at baseline (1993), except retirement that was use as time-varying covariates in the analysis. [PY=person-years; IR=incidence rate; HR=hazard ratio; $\mathrm{Cl}=$ confidence interval]

\begin{tabular}{|c|c|c|c|c|c|c|c|c|c|c|c|c|}
\hline \multirow{2}{*}{$\begin{array}{l}\text { Occupational } \\
\text { trajectories }\end{array}$} & \multirow{2}{*}{$\begin{array}{l}\text { N suicide } \\
\text { death/N }\end{array}$} & \multirow[t]{2}{*}{ PY } & \multirow{2}{*}{$\begin{array}{c}\text { IR per } \\
100000 \mathrm{PY}\end{array}$} & \multicolumn{3}{|c|}{ Model $1^{\text {a }}$} & \multicolumn{3}{|c|}{ Model $2^{b}$} & \multicolumn{3}{|c|}{ Model $3^{c}$} \\
\hline & & & & $\mathrm{HR}$ & $95 \% \mathrm{Cl}$ & P-value & HR & $95 \% \mathrm{Cl}$ & P-value & $\mathrm{HR}$ & $95 \% \mathrm{Cl}$ & P-value \\
\hline \multicolumn{13}{|l|}{$\begin{array}{l}\text { End of follow-up } \\
\text { at } 70 \text { years }\end{array}$} \\
\hline Trajectory $1^{\mathrm{d}}$ & $12 / 1755$ & 34224 & 35.06 & 2.54 & $1.06-6.07$ & 0.036 & 2.34 & $0.98-5.61$ & 0.057 & 2.01 & $0.82-4.92$ & 0.127 \\
\hline Trajectory $2^{\mathrm{e}}$ & $10 / 2315$ & 45488 & 21.98 & 1.67 & $0.67-4.13$ & 0.269 & 1.61 & $0.65-4.01$ & 0.302 & 1.49 & $0.59-3.75$ & 0.393 \\
\hline Trajectory $3^{f}$ & $39 / 12434$ & 251458 & 15.51 & 1.52 & $0.73-3.18$ & 0.263 & 1.45 & $0.69-3.02$ & 0.324 & 1.35 & $0.64-2.85$ & 0.429 \\
\hline Trajectory $4 \mathrm{~g}$ & $9 / 3948$ & 79628 & 11.30 & & reference & & & reference & & & reference & \\
\hline \multicolumn{13}{|l|}{$\begin{array}{l}\text { End of follow-up } \\
\text { at } 65 \text { years }\end{array}$} \\
\hline Trajectory $1^{\mathrm{d}}$ & $10 / 1755$ & 28826 & 34.69 & 2.07 & $0.83-5.14$ & 0.116 & 1.89 & $0.76-4.71$ & 0.170 & 1.62 & $0.64-4.12$ & 0.313 \\
\hline Trajectory $2^{\mathrm{e}}$ & $8 / 2315$ & 37301 & 21.45 & 1.34 & $0.51-3.46$ & 0.564 & 1.28 & $0.49-3.34$ & 0.619 & 1.19 & $0.45-3.13$ & 0.734 \\
\hline Trajectory $3^{f}$ & $38 / 12434$ & 215547 & 17.63 & 1.46 & $0.70-3.05$ & 0.318 & 1.38 & $0.66-2.89$ & 0.394 & 1.29 & $0.61-2.73$ & 0.509 \\
\hline Trajectory $4 \mathrm{~g}$ & $9 / 3948$ & 66454 & 13.54 & & reference & & & reference & & & reference & \\
\hline
\end{tabular}

${ }^{a}$ Adjusted for socio-demographic characteristics (sex, partner status, retirement).

${ }^{\mathrm{b}}$ Adjusted for health behaviors (smoking, alcohol use).

${ }^{\mathrm{c}}$ Adjusted for psychosocial characteristics (stressful life events, depressive symptoms, cognitive hostility).

d Stable manual workers.

${ }^{\text {e }}$ Manual workers with career development.

${ }^{\mathrm{f}}$ Clerks with career development.

g Participants with intermediate/high occupational grade with career development.

Table 5. Association between occupational grade at baseline (1993) and risk of suicide (1993-2014): the GAZEL cohort study, N=20 452, Cox proportional-hazards regression models. Results are of participants with imputed missing data. Confounding variables were used at baseline (1993), except retirement that was use as time-varying covariates in the analysis. [PY=person-years; IR=incidence rate; $\mathrm{HR}=$ hazard ratio; $\mathrm{Cl}=$ confidence interval].

\begin{tabular}{|c|c|c|c|c|c|c|c|c|c|c|c|c|}
\hline \multirow{2}{*}{$\begin{array}{l}\text { Occupational grade at } \\
\text { baseline (1993) }\end{array}$} & \multirow{2}{*}{$\begin{array}{l}\mathrm{N} \text { suicide } \\
\text { death/N }\end{array}$} & \multirow[t]{2}{*}{ PY } & \multirow{2}{*}{$\begin{array}{l}\text { IR per } \\
100000 \mathrm{PY}\end{array}$} & \multicolumn{3}{|c|}{ Model $1^{\text {a }}$} & \multicolumn{3}{|c|}{ Model $2^{b}$} & \multicolumn{3}{|c|}{ Model $3^{c}$} \\
\hline & & & & $\mathrm{HR}$ & $95 \% \mathrm{Cl}$ & P-value & $\mathrm{HR}$ & $95 \% \mathrm{Cl}$ & P-value & $\mathrm{HR}$ & $95 \% \mathrm{Cl}$ & P-value \\
\hline Manual worker & $9 / 1529$ & 31156 & 28.89 & 2.58 & $1.07-6.27$ & 0.036 & 2.41 & $0.99-5.87$ & 0.052 & 2.05 & $0.83-5.07$ & 0.122 \\
\hline Clerk & $5 / 1841$ & 38581 & 12.96 & 2.27 & $0.76-6.83$ & 0.143 & 1.99 & $0.66-6.00$ & 0.219 & 1.64 & $0.53-5.02$ & 0.389 \\
\hline Intermediate grade ${ }^{d}$ & $48 / 11507$ & 242150 & 19.82 & 2.34 & $1.20-4.53$ & 0.012 & 2.22 & $1.14-4.31$ & 0.019 & 2.03 & $1.04-3.99$ & 0.039 \\
\hline High grade ${ }^{e}$ & $11 / 5575$ & 118422 & 9.29 & & reference & & & reference & & & reference & \\
\hline
\end{tabular}

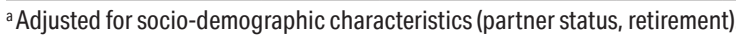

${ }^{\mathrm{b}}$ Adjusted for health behaviors (smoking, alcohol use).

${ }^{\mathrm{c}}$ Adjusted for psychosocial characteristics (stressful life events, depressive symptoms, cognitive hostility).

d Intermediate grade: associate professionals and technicians.

e High grade: managers.

Additional adjustment for health behaviors (Model 2) and psychosocial characteristics (Model 3) reduced the magnitude of these associations leaving only the association between participants with intermediate grade and risk of suicide statistically significant ( $\mathrm{HR}=2.03,95 \%$ CI 1.04-3.99). Overall, the results were different from the main analysis.

\section{Discussion}

Using data from a 20456 middle-aged workers participating in a long-term cohort study, we identified four career-long occupational trajectories, of which one was characterized by persistent low occupational grade with no career development and three identified individuals who experienced career development. Over the course of a 22-year follow-up, compared to workers with intermediate/high occupational grade who experienced career development, stable manual workers were at elevated risk of suicide. In addition, manual workers and clerks with career development displayed intermediate levels of risk, suggesting a gradient between career-long trajectories and suicide. This association was partly explained by psychosocial characteristics such as depression, stressful life events and personality characteristics. Finally, we showed that suicide risk associated with occupational trajectories was different than suicide risk associated with occupational grade at one point in time.

To our knowledge, this is the first study to explore the association between long-term occupational trajectories and suicide, showing that beyond occupational characteristics at one specific point in time, long-term 
employment patterns shape suicide risk. The present findings should be interpreted in light of some limitations. First, although the GAZEL cohort covers most regions of France and a wide range of occupations, it is not representative of the general population. In particular, GAZEL only included salaried workers (farmers, the self-employed, the unemployed, or individuals with unstable jobs are not in the sample) and EDF-GDF employees did not experience downward career mobility or job loss. Additionally, GAZEL participants have been shown to be in better health than EDF-GDF employees and the general population of France (11). Lower mortality by suicide was observed in the GAZEL cohort compared to the French population with the same age and with similar follow-up, with a standardized mortality ratio for suicide of 0.72 [0.58-0.89]. Thus, relations between occupational trajectories and suicide in the population at large may be stronger than we report. Second, given the limited number of suicides in our study, our analyses may have lacked statistical power. Thus, the association between occupational trajectory and suicide became statistically non-significant after controlling for psychosocial characteristics, but the HR was nevertheless 2.02. Moreover, due to the trajectory profiles of the population studied, we were only able to compare stable trajectory and career development trajectory in manual workers. Our results indicate that stable manual workers had a higher risk of suicide than manual workers with career development but the difference was not statistically significant suggesting that more statistical power is needed to compare stable and upward career trajectories; therefore confounding by occupational grade cannot be ruled out. Third, the use of ICD codes to identify suicide deaths could be conservative, as coders may use alternative options when available (1). Fourth, although we controlled for a wide range of potentially confounding variables, we cannot exclude the possibility of residual confounding from unmeasured variables, such as prior suicide attempts.

Despite these limitations, the main strengths of this study include the large number of participants, a longitudinal design, complete data on participants' mortality, and the possibility to control for key confounders. This study makes a unique contribution by suggesting that career-long occupational trajectories are associated to the risk of suicide over an extended follow-up period. It also underscores the importance of considering occupational trajectories rather than only occupational grade at one point in time in studies aimed at examining the role of long-term factors in relation to the risk of suicide in order to identify who is most at highest risk and to prevent suicide.

Persistently low occupational grade could be related to an elevated risk of suicide. The role of psychosocial characteristics such as depression and personality traits in this association suggests that some individuals could be especially vulnerable to the consequences of limited opportunities for occupational advancement. Moreover, the lack of career development could also contribute to depressive symptoms and hostility. Further studies are needed to identify specific aspects of the occupational environment that may contribute to the excess risk of suicide associated with persistent low occupational grade and ways to protect the most vulnerable workers.

\section{Acknowledgments}

The authors express their thanks to Electricite de France and Gaz de France, especially to the Service Général de Médecine de Contrôle, and to the Caisse Centrale d'Action Sociale du Personnel des Industries Électrique et Gazière. We also acknowledge the Mixed Service Unit 11 of INSERM and the Université Versailles SaintQuentin for the management of the GAZEL database.

\section{Sources of financial support}

The GAZEL cohort study was funded by Electricité de France, Gaz de France, and the Institut national de la santé et de la recherche médicale (INSERM) and received grants from the program Très Grandes Infrastructures de Recherche, the Agence Nationale de la Recherche (ANR), and the Agence Française de Sécurité Sanitaire de l'Environnement et du Travail (AFSSET).

The present analyses were funded by the Institut de Recherche en Santé Publique (IReSP) call for projects "Suicide et prévention du suicide" in 2015.

\section{Informed consent}

Informed consent was obtained from all individual participants included in the study.

\section{Conflict of interest}

The authors declare no conflicts of interest.

\section{References}

1. World Health Organization. Preventing suicide: A global imperative [Internet]. 2014. Available from: http://www.who. int/mental_health/suicide-prevention/world_report_2014/ en/.

2. Schneider B, Grebner K, Schnabel A, Hampel H, Georgi $\mathrm{K}$, Seidler A. Impact of employment status and workrelated factors on risk of completed suicide. A casecontrol psychological autopsy study. Psychiatry Res 
2011 Dec;190(2-3):265-70. http://dx.doi.org/10.1016/j. psychres.2011.07.037.

3. Milner A, Page K, Spencer-Thomas S, Lamotagne AD. Workplace suicide prevention: a systematic review of published and unpublished activities. Health Promot Int 2015 Mar;30(1):29-37. http://dx.doi.org/10.1093/heapro/ dau085.

4. Klingelschmidt J, Milner A, Khireddine-Medouni I, Witt $\mathrm{K}$, Alexopoulos EC, Toivanen S et al. Suicide among agricultural, forestry, and fishery workers: a systematic literature review and meta-analysis. Scand J Work Environ Health 2018 Jan;44(1):3-15. http://dx.doi.org/10.5271/ sjweh.3682.

5. Milner A, Spittal MJ, Pirkis J, LaMontagne AD. Suicide by occupation: systematic review and meta-analysis. Br J Psychiatry J Men Sci. 2013 Dec;203(6):409-16.

6. Baumert J, Schneider B, Lukaschek K, Emeny RT, Meisinger C, Erazo $\mathrm{N}$ et al. Adverse conditions at the workplace are associated with increased suicide risk. J Psychiatr Res 2014 Oct;57:90-5. http://dx.doi.org/10.1016/j. jpsychires.2014.06.007.
7. Goldberg M, Leclerc A, Zins M. Cohort Profile Update: The GAZEL Cohort Study. Int J Epidemiol 2015 Feb;44(1):7777g. http://dx.doi.org/10.1093/ije/dyu224.

8. Lemogne C, Fossati P, Limosin F, Nabi H, Encrenaz G, Bonenfant $\mathrm{S}$ et al. Cognitive hostility and suicide. Acta Psychiatr Scand 2011 Jul;124(1):62-9. http://dx.doi. org/10.1111/j.1600-0447.2010.01658.x.

9. Nagin D. Group-Based Modeling of Development. Harvard University Press; 2005.

10. van Buuren S. Multiple imputation of discrete and continuous data by fully conditional specification. Stat Methods Med Res 2007 Jun;16(3):219-42. http://dx.doi. org/10.1177/0962280206074463.

11. Goldberg M, Chastang JF, Leclerc A, Zins M, Bonenfant S, Bugel I et al. Socioeconomic, demographic, occupational, and health factors associated with participation in a long-term epidemiologic survey: a prospective study of the French GAZEL cohort and its target population. Am J Epidemiol 2001 Aug;154(4):373-84. http://dx.doi. org/10.1093/aje/154.4.373.

Received for publication: 15 May 2018. 